\title{
Perspectivas do PRINCíPIO da EFETIVIdAde NA JURISDiÇÃo CONTEMPORÂNeA
}

\author{
Effectiveness principal perspectives in contemporary jurisdiction
}

\section{JÚlia IzaBel BarRetoEtinger}

Graduanda do curso de Direito pela Universidade Tiradentes (UNIT) de Aracaju/ SE.E-mail juliaizabel@hotmail.com.

\section{Martha Franco Leite}

Professora dos cursos de graduação e pós-graduação em Direito da Universidade Tiradentes (UNIT-Aracaju/SE), especialista em Direito processual e em Didática do Ensino Superior. E-mail: martha-franco@hotmail.com.

RECEBIDO EM: 01.08.2013

APROVADO EM: 30.08 .2013

\section{RESUMO}

A análise da efetividade desenvolvida neste artigo tem o objetivo de delinear o atual panorama do Processo Civil Brasileiro. Urge definir o modo pelo qual a efetividade possa ser realmente aplicada na dinâmica processual, principalmente no que se refere às tutelas jurisdicionais concedidas. Para tanto, são expostas algumas situações que dizem respeito ao processo e esbarram na sua efetividade. Ao mesmo tempo, tratar sobre efetividade tem extrema pertinência no atual contexto de renovação do Processo Civil para que seja possível repensar o sentido do instrumento que é o processo. Tal investigação será traçada através dos estudos bibliográficos, abordando os conceitos clássicos necessários àcompreensãodo tema. Os novos enfoques também constituem elementos imprescindíveis neste estudo, pois com eles é possível repensar a efetividade processualística, sem descuidar dos avanços e das novas alternativas inerentes ao Direito Processual. O percurso pretendido é, inicialmente, a definição dos conceitos elementais para que se possa chegar à exposição das principais situações processuais que afetam a efetividade da Jurisdição e, principalmente, do processo. Com efeito, o resultado deste estudo comparativo servirá para traçar metas no aprimoramento do sistema processual, tendo como princípio norteador a efetividade dos institutos e dos procedimentos em apreciação. 
Palavras-chave: Efetividade. Jurisdição. Processo. Tutela Jurisdicional. AplicaBILIDADE.

\begin{abstract}
The effectiveness analysis developed in this paper aims to delineate the Brazilian Civil Procedure current panorama. Urge to define the way in which the effectiveness can be actually applied in procedural dynamics, especially in what it refers to granted court custodies. For that, will be expose some procedure situations that concern the process and ran into their effectiveness. At the same time, we shall treat about how effectiveness has high pertinence in Civil Procedure nowadays renovation, so it will be possible rethink process as an instrument. This investigation will be track through bibliographic studies, approaching necessary classical concepts to this topic comprehension. In this work new approaches also establish indispensable elements, because with them it's possible rethink civil procedural effectiveness without ignore Procedural Law progresses and new alternatives. The path chosen is, initially, elemental concepts definition to reach the exposition of main procedural situations that affect the Jurisdictional effectiveness and mostly from process. As a matter of fact, this comparative study result will serve to set goals to improve procedural system having as northern principal the institutions and procedural effectiveness.
\end{abstract}

Keywords: Effectiveness. Jurisdiction. Process. Court custody. Applicability.

Sumário: 1 . O princípio da efetividade e a sua pertinência na sistemática jurídica. 1.1. O direito e a efetividade. 1.2. A efetividade com enfoque na tutela jurisdicional. 1.3. Necessidade da efetividade no mundo jurídico- base constitucional no direito brasileiro. 1.4. A efetividade no contexto processual. 2. Interferências da sistemática processual na efetividade jurídica. 2.1. A estrutura processual e o formalismo na atividade jurisdicional. 2.2. A consciência jurídica na aplicação do direito. 2.3. Inovação processual: motivos e repercussão na jurisdição. Conclusão. Referências.

\title{
INTRODUÇão
}

A análise contida neste trabalho tem como principal foco o princípio e instrumento que é a Efetividade dentro da processualística civil, pois discutir efetividade é buscar entender o meio pelo qual os institutos processuais atingem seus objetivos primordiais, algo imprescindível para o Direito. Portanto, faz-se uma exposição sobre o conceito de Efetividade no Processo Civil, as teorias que a circundam, bem 
como seus desdobramentos, para que seja possível investigar com maior clareza a aplicabilidade deste princípio processual.

O problema principal está em definir de que modoa estrutura que envolve atualmente o processo atende eficazmente à efetivação e concretização das tutelas jurisdicionais. Neste contexto, grande parte do estudo está voltado para a análise de algumassituações em torno da processualísticaas quaisinviabilizam a fiel aplicação do princípioda efetividade.

Este tema tem grande pertinência na sociedade contemporânea, pois trata de questão que está no centro das discussões processuais, uma vez que se delibera na esfera federal sobre a renovação do Código de Processo Civil. Assim, os olhares jurídicos se voltam para a aplicabilidade e finalidade dos instrumentos do processo e dentro deste contexto é relevanteobservar a aplicação da efetividade ao processo.

Não seria coerente concordar com a ideia de um instrumento do Direito que não alcançasse os objetivos desejados, nem foi este o desejo do legislador constituinte na Carta Magna ao indicar o processo como meio adequado para se obter uma tutela jurisdicional. É certo que o processo tem como intento trazer ao seio social a pacificação, sendo através dele possível tutelar, coibir e proteger determinados tipos de interesse. É necessário, portanto, que o meio de concretizar o Direito seja idôneo e possa trazer resultados de fato. A isso no mundo jurídico se denomina efetividade.

Com isto, busca-se trazer com este estudo uma percepção renovada do direito processual. Além das soluções momentâneas e alterações legislativas pontuais, é necessária a renovação do pensamento jurídico tanto do ponto de vista legislativo quanto das práticas dos operadores do Direito. Para tanto, a metodologia deste trabalho é baseada na revisão bibliográfica partindo dos registros doutrinários a respeito do tema estudado. A pesquisa está sustentada numa análise do que já foi escrito sobre o tema, mas também nas leis vigentes e nas próprias normas principiológicas das quais deriva o Princípio da Efetividade. Deste modo, com a análise conceitual do tema Efetividade busca-se definir quais os principais limites à sua aplicabilidade na processualística atual.

Enfim, embora o tema possua um número elevado de desdobramentos a pesquisa detém-se naquilo que se constitui como bloqueio à Efetividade processual.

\section{O PRINCÍPIO DA EFETIVIDAdE E A SUA PERTINÊNCIA NA SISTEMÁTICA JURÍdICA}

O que é efetividade processual? Inicia-se a investigação partindo do conceito de efetividade e para isso é necessário entender tanto o sentido léxico do termo quanto aquele que se insere no mundo jurídico.

Numa análise do vocábulo efetivo, o Dicionário Aurélio (2004) traz a definição daquele adjetivo que determina a característica do que existe realmente, o que é verdadeiro, real, positivo. O termo advém do latim effectivusignificando aquilo que é ativo ou que produz algo. Portanto, a palavra efetividade - uma derivação que 
indica o estado das coisas - tem o condão de classificar algo que possui concretude, ou seja, existe e interfere diretamente no mundo real.

O conceito jurídico não se ajusta totalmente ao sentido vocabular do termo. Efetividade jurídica representa a capacidade de a norma ser atendida tanto pelos destinatários, quanto pelos aplicadores do Direito. É indispensável, então, o cumprimento por parte dos indivíduos daquilo que está prescrito no ordenamento para que se alcance a efetividade, elemento este que se correlaciona à eficácia (NADER, 2009, pp. 110-111).

Para uma melhor aplicação da norma ao caso concreto é fundamental entender de que tratam os conceitosprincipiológicos. Assim sendo, o positivismo jurídico é método esclarecedor porque delimita o objeto da investigação e esquadrinha os seus principais aspectos. Hans Kelsen, expoente desta linha teórica, consegue especificar o sentido do princípio da Efetividade dentro da constituição de uma norma. A sua definição para efetividade posiciona opreceito dentro no contexto do Estado. Daí a análise também estar relacionada com a Teoria do Estado, pois o autor entende que a efetividade é condição dasregras que constituem o meio normativo social.

Os conceitos são bem delimitados por Kelsen (1997, p.233) na Teoria Pura do Direito, ao tratar sobre a chamada norma fundamental da qual provém os alicerces de observância da ordem legal pela sociedade. Ele explica, através do exemplo da tomada de poder num certo Estado, que a ordem jurídica (governo) eivada de efetividade será baseada em normas gerais e individuais. Nesse exemplo, os conceitos de validade e eficácia estão unidos ao que define como efetividade.

A norma fundamental refere-se apenas a uma Constituição que é efetivamente estabelecida por um ato legislativo ou pelo costume que é eficaz. Uma Constituição é eficaz se as normas postas de conformidade com ela são, globalmente e em regra aplicadas e observadas (KELSEN, 1997, p. 234) (grifou-se).

Portanto, a efetividade do Direito possui em torno de si outros caracteres que precisam ser observados. Contudo, os conceitos não se confundem e não possuem o mesmo significado. Exemplo disto é que a validade, aspecto inerente da efetividade, éapenas um dos elementos desta, não a constituindo por completo. E, como pressuposto da própria validade, encontra-se também a eficácia supramencionada, dos normativos:

Tal eficácia é condição no sentido de que uma ordem jurídica como um todo e uma norma jurídica singular já não são consideradas como válidas quando cessam de ser eficazes. Mas também a eficácia de uma ordem jurídica não é, tampouco como o fato que a estabelece, fundamento de validade. Fundamento de validade, isto é, a resposta à questão de saber porque 
devem as normas desta ordem jurídica ser observadas e aplicadas, é a norma fundamental pressuposta segundo a qual devemos agir em harmonia com uma Constituição efetivamente posta, globalmente eficaz, e, portanto, de harmonia com as normas efetivamente postas de conformidade com esta Constituição e globalmente eficazes (KELSEN, 1997, p. 236).

Os conceitos estão bastante intrincados, mas são sempre observados segundo a norma hipotética fundamental, a qual seria para Kelsen o fundamento de validade de todo o ordenamento jurídico. Deste estudo proposto pelo jurista, observando a norma dentro da organização do Estado, percebe-se que efetividade é o acolhimento dos preceitos pelos indivíduos, validade é o mesmo que observância e aplicabilidade e eficácia constitui um dos atributos da validade. A distinção não se apega ao aspecto friamente teórico, mas influencia sobremaneira na análise do ordenamento jurídico em meio à sociedade.

\subsection{O DIREITO E A EFETIVIDADE}

Qual seria o intuito de se obedecer às regras postas? Deste questionamento surge a necessidade de entender o que fundamenta o arcabouço jurídico e porque ele deve ser respeitado, ou seja, entender também sua validade. Chegar a este ponto corresponde ao início do percurso pelo qual se chega à efetividade.

A Constituição diz que o poder emana do povo (Art. $1^{\circ}$, parágrafo único, $\mathrm{CF} / 88$ ), por isso as leis são meios de transcrição do poder através da representação popular. No panorama atual, por diversas vezes se percebe que a vontade popular nem sempre é redigida no texto legal, ou, se é, não consegue amparar e efetivar verdadeiramente os anseios da sociedade. Entretanto, isto não descaracteriza o aspecto formal do sistema de instituição das normas em geral. Respondendo à pergunta inicial, os indivíduos se submetem a estas normas, dentre outros fatores, porque desejam ver de fato atendidas as suas pretensões na sociedade, por isso a importância do ordenamento jurídico.

A partir do momento em que o Estado retira do indivíduo o poder de autotutela ele agrega para si a função de dirimir os conflitos e atender as demandas sociais. Cedida ao Estado a organização da sociedade, os seus representados pretendem receber deste ente uma resposta efetiva, seja nas leis, seja na resolução dos conflitos, seja na execução das tarefas a ele incumbidas. Consequentemente, o Direitocomo ciência normativa social e estatal tem como um dos seus objetivos tornar aquilo que é legislado cada vez mais efetivo, em termos de resposta aos cidadãos.

Neste sentido é que a efetividade possui tamanha importância. Não basta que o Estado agregue para si as funções de legislador, julgador e executor. Estas se tornam inócuas quando destituídas de concretude. Aaplicabilidade, como explanado alhures, depende da eficácia e da validade no mundo jurídico e o Estado, como gran- 
de protetor das garantias do cidadão, deve ter tais premissascomo baliza. Observando esta situação, sobreleva que de nadavale um direito existente formalmente e que, por falta dos requisitos essenciais, inexiste materialmente.

\subsection{A EFETIVIDADE COM ENFOQUe Na TUTELA JURISDiCiOnAL}

O cidadão almeja ser concretamente atendido nas relações jurídicas que estabelece dentro do Estado, quer isto envolva uma litigiosidade, quer não envolva. No que toca ao aspecto jurisdicional, imprescindível é que no momento em que o Poder Judiciário é chamado à resolução dos conflitos ele esteja aparatado com as ferramentas necessárias à melhor composição das controvérsias. A efetividade, nesse contexto é tomada como paradigma de atuação. A análise começa então a se voltar para a tutela jurisdicional e a forma como ela é operacionalizada.

A Jurisdição é o meio pelo qual o Estado exerce o seu poder de regulamentar as relações sociais que estão dissonantes do sistema legal vigente. Não existe qualquer nação que prescinda da atividade jurisdicional, porque na sociedade se compartilham diversos interesses que podem estar amparados por direitos ou não. Em algum momento, tais interesses podem colidire disto advém a importância desse poder Estatal. É seu papel regulamentar aquelas situações que geram um estado de desarmonia social, atingindo esferas de direitos.

Como exercício de um poder, o processo sofre influências as mais diversas, principalmente políticas.

O significado político do processo como sistema aberto, voltado à preservação dos valores postos pela sociedade e afirmados pelo Estado, exige que ele seja examinado também a partir de uma perspectiva externa; exige uma tomada de consciência desse universo axiológico a tutelar e da maneira como o próprio Estado define a sua função e atitude perante tais valores (DINAMARCO, 2002, p. 99).

Percebe-se, portanto, a importância da política dentro da Jurisdição, pois ela define os paradigmas norteadores da atividade judicante. Assim a política, que é considerada pelo autor como a "arte do possível", seria um espelho da jurisdição que, ao tutelar, implica no favorecimento do interesse de um e sacrifício do de outro ${ }^{235}$.

Porém este entendimento é questionável ao seconsiderar que a busca da jurisdição é pelapacificaçãodos conflitos sociais gerandoo maior grau de satisfação possível entre as partes. É claro que algum dos litigantes verá atingida a sua pretensão oposta em juízo, entretanto isto não constitui fator motivador para que todos os litígios em juízo tenham sistemática semelhante a das possibilidades políticas. É

\footnotetext{
${ }^{235}$ Ao utilizar o termo arte do possível, Dinamarco (2002, pp.100-101) se refere à jurisdição como um quadro de alternativas, o qual está à disposição do julgador que, em sua decisão, deve se pautar pela viabilidade, menor custo e maior eficácia.
} 
inegável a influência do poder político, contudo a jurisdição se preocupa antes com a harmonia social, e isto envolve, casuisticamente, uma aplicação humanizada do ordenamento jurídico. Essa postura, por vezes, não é objeto da ação política, já que neste campo as questões tendem a uma repercussão geral, abstrata e quantitativa.

A efetividade da jurisdição, então, se volta para a compreensão de que o direito a ser aplicado ao caso é primeiramente aquele a ser aplicado ao indivíduo. Não se pode olvidar da influência que as escolhas sociais têm sobre a legislação em vigor, contudo a efetividade da norma não depende exclusivamente do plano geral e político. À frente do macro aspecto, a aplicação da norma na situação concreta e a escolha jurisdicional dependerão fundamentalmente dainterpretação que é dada à estrutura teórica.

Logo, a atividade jurisdicional ao positivar um direito numa lide poderá ser efetiva ou não. A importância da avaliação dos principais fatores que envolvem a concessão de uma tutela jurisdicional está em observar o momento em que esta tutela deixa de ser efetiva, a fim de buscar soluções para o seu aperfeiçoamento.

Em tudo isto, a realização da harmonia social, objetivo primeiro da jurisdição,é farol para a efetividade da tutela jurisdicional. Mesmo que não seja possível alcançar a harmonia entre os sujeitos da lide, o empenho do Estado-juiz nesta tarefa faz parte do processo de efetivação dos direitos e da própria Jurisdição.

\subsection{NeCESSIDADE DA EFETIVIDADE NO MUNDO JURÍDICO- BASE CONSTITUCIONAL NO DIREITO BRASILEIRO}

A efetividade, considerada como princípio, tem extrema importância no cenário jurídico, pois é paradigma que regulamenta a atuação jurisdicional. Tal princípio tem matriz constitucional porque advém de dois outros pilares para o direito processual instituídos na Carta Magna como direitos fundamentais: o Devido Processo Legal (art.5 $5^{\circ}$ LIV, CF) e o Acesso à Justiça (art. $\left.5^{\circ}, \mathrm{XXV}, \mathrm{CF}\right)$.

Devido Processo Legal é uma das principais garantias existentes no Direito. Esta norma se aplica a todo o ordenamento jurídico e visa resguardar os cidadãos do arbítrio do Estado e dos outros indivíduos que convivem no seio social. Hoje já se entende que este princípio tem aplicabilidade no campo doDireito Público, como também no das relações privadas. A partir disto, fica perceptível que este instrumento deve ser observado pelos vários ângulos da sistemática jurídica.

Tamanha é a sua aplicabilidade que o princípio se divide em dois aspectos: o formal, que está relacionado à questão da proporcionalidade, e o material que diz respeito ao aspecto estrutural das formas em si. A sua materialidade indica que não basta só a regularidade formal, pois o processo deve ser substancialmente razoável e correto. (DIDIER, 2009, p.38). De igual modo, esta premissa da forma é o que assegura a lisura do procedimento, a fim de que ele não sofra ingerências indevidas e nem esteja vulnerável às vontades que não se coadunam com o ordenamento jurídico 
vigente. Segundo Tucci (apud DIDIER, 2009, p.38):

Em síntese, a garantia constitucional do devido processo legal deve ser uma realidade durante as múltiplas etapas do processo judicial, de sorte que ninguém seja privado de seus direitos, a não ser que no procedimento em que se materializa se constatem todas as formalidades e exigências em lei previstas.

Estes caracteres supramencionados do princípio do Devido Processo Legal têmcomo consectários o Acesso à Justiça e a própria Efetividade. Daí porque, mesmo a Efetividadenão sendo originadana Carta Magna, dela decorre, pois seus princípios informadoresemanam da previsão constitucional.

Quanto ao princípio do Acesso à Justiça, este não busca apenas garantir aos indivíduos a capacidade de propor suas demandas. Primeiro porque a litigância em juízo por si só não é o fim desejado pelo cidadão que busca o Judiciário. Primordialmente, ele busca solucionar o seu conflito. Nem o litígio, nem a litigância em juízosãofins em si mesmos. Por isso, não se pode considerar que o acesso à jurisdição pura e simplesmente seja o fato desejado pelo jurisdicionado. Antes, o desejo é de que a resolução da sua demanda seja procedida de forma efetiva. Isto sim é o verdadeiro acesso à jurisdição. Doutro modo, seria considerar que a mera propositura da ação já assegura ao cidadão a efetividade dos seus direitos, o que por si só constitui uma premissa inadequada.

Atualmente, os meios de acesso à justiça estão bastante amplos, previsão feita por Capelletti (2002, p.15) em sua obra Acesso à Justiça. Exemplo disso é o instituto dagratuidade judiciária, o patrocínio da defesa dos desfavorecidos economicamente por uma instituição estatal gratuita, a Defensoria Pública, a competência específica e mais célere para as causas que possuem menor proporção, dentre outras inovações que possibilitam o acesso ao Judiciário.

Contudo, a Efetividade hoje não tem como centro primordial de discussão o acesso enquanto entrada, mas o acesso ao conteúdo material da tarefa do poder Judiciário, que é o provimento jurisdicional. O Princípio da Efetividade é a base de uma segunda vertente do acesso judicial previsto na Constituição: a concretude da tutela concedida. Por isso a importância de visualizar dentro da jurisdição tal efetividade, pois o princípio do Acesso à Justiça tem o seu conteúdo reforçado, seja ele no aspecto da propositura da demanda em juízo, seja no resultado da manifestação do Judiciárioa respeito dela.

A expressão acesso à justiça é reconhecidamente de difícil definição, mas serve para determinar duas finalidades básicas do sistema jurídico - o sistema pelo qual as pessoas podem reivindicar seus direitos e/ou resolver seus litígios sobe os auspícios do Estado. Primeiro o sistema deve ser 
igualmente acessível a todos; segundo, ele deve produzir resultados que sejam individual e socialmente justos (CAPELLETTI, 2002, p.8).

Unificando os conceitos explanados, percebe-se que em algum momento eles desembocam no que se tem por Princípio da Efetividade no processo civil. Por isso a pertinência e a necessidade deste paradigma dentro do ordenamento jurídico.

Aquilo que se busca instituir por meio dos princípios jurídicos de base constitucional tem por fim atingir a concretude do Direito, que nada mais é que a sua efetividade no seio social. Assim, a busca por uma Jurisdição mais efetiva tem extrema relevância dentro do processo e os conceitos acima delineados devem ser observados em torno da sistemática processual vigente.

\subsection{A EFETIVIDADE No CONTEXTO PROCESSUAL}

Tratar de processo significa observar o meio como o direito chega até as partes integrantes de um litígio. A Jurisdição se interessa por este instrumento por ser ele o método pelo qual é possível operacionalizar da forma mais adequada o direito envolvido na lide. Justamente por isto é que Chiovenda já anunciava que o processo deve dar a quem tenha razão o exato bem da vida a que ele tenha direito, o que faz com que o princípio da efetividade seja conhecido também como o da máxima coincidência possível (DIDIER, 2009, pp. 39-40).

Mas não há estudo que defina com maior clareza lógico-metodológica e prática o que é um processo efetivo do que aquele elaborado por Barbosa Moreira (apud CÂMARA, 2009, pp. 27-28) em seu trabalho sobre a efetividade do processo. Ele estabelece as premissas que resumem como deve se pautar a atividade jurisdicional em torno do processo:

a) o processo deve dispor de instrumentos de tutela adequados, na medida do possível, a todos os direitos (e outras posições jurídicas de vantagem) contemplados no ordenamento, quer resultem de expressa previsão normativa, quer se possam inferirdo sistema;

b) esses instrumentos devem ser praticamente utilizáveis, ao menos em princípio, sejam quais forem os supostos titulares do direito (e das outras posições jurídicas de vantagem) de cuja preservação ou reintegração se cogita, inclusive quando indeterminado ou indetermináveis o círculo dos eventuais sujeitos;

c) impende assegurar condições propícias à exata e completa reconstituição dos fatos relevantes, a fim de que o convencimento do julgador corresponda, tanto quanto puder, à realidade;

d) em toda a extensão da possibilidade prática, o resultado do processo há de ser tal que assegura à parte vitoriosa o gozo pleno da específica utilidade 
a que faz jus segundo o ordenamento;

e) cumpre que se possa atingir semelhante resultado com o mínimo dispêndio de tempo e energias.

É notório que, em suas noções, Moreiraestabelece pontos nos quais o processo deve receber maior atenção, mas nunca regras procedimentais engessadas. Isto porque,o conceito de efetividade fornece ao seu aplicador certa liberdade na interpretaçãodo processo para que seja possível alcançar uma tutela cada vez mais adequada. Nesta atividade do juris dicere, os procedimentos utilizados devem servir, primeiramente, aos objetivos gerais do Direito para que eles não fiquem destituídos de sentido.

Entendendo o objetivo do processo (pacificação social) chega-se à concepção de que a Efetividade processual deve não só ser um meio de fazer cumprir e observar o direito in concreto, mas, precipuamente, meio para que a tutela jurisdicional seja absorvida pelos envolvidos. Efetividade caracteriza também a existência de uma jurisdição que é apropriada para os indivíduos, de modo a realizar o direito que lhes "pertence", nem que este seja, v.g., o de defesagarantido no Contraditório. Isso significa efetivar, além do processo em si,o direito dos indivíduos, inclusive daqueles aos quais se opõe alguma pretensão. Uma tomada de posição como esta garante ao Judiciário a credibilidade e legitimidade em seus atos quando aplicados aos jurisdicionados.

O importante não é o consenso em torno das decisões estatais, mas a imunização delas contra os ataques dos contrariados; e indispensável, para cumprimento da função pacificadora exercida pelo Estado legislando ou sub speciejurisdictionis é a eliminação do conflito como tal, por meios que sejam reconhecidamente idôneos. O que importa, afinal, é 'tornar inevitáveis e prováveis decepções em decepções difusas: apesar de descontentes as partes aceitam a decisão'. Elas sabem que, exauridos os escalões de julgamento, esperança alguma de soluções melhor seria humanamente realizável; além disso, ainda que inconscientemente, sabem também que necessitam da proteção do Estado e não convém à tranquilidade de ninguém a destruição dos mecanismos estatais de proteção mediante a sistemática desobediência (DINAMARCO, 2002, p.195).

\section{INTERFERÊNCIAS DA SISTEMÁTICA PROCESSUAL NA EFETIVIDADE JURÍDICA}

Depois de haver sido traçado o panorama a respeito da efetividade no mundo jurídico, bem como a sua correlação com o processo, a investigação deve atingir aquilo que concretamente interfere na efetividade do sistema processual.

Esta análise é chamada de interferências da sistemática processual na efe- 
tividade jurídica uma vez que esse princípio é instrumentalizado pelas práticas procedimentais. Também não perde o sentido caso seja chamada de entraves procedimentais à efetividade jurídica. Tal reciprocidade nominal é válida, pois o estudo se preocupa não somente em definir o conteúdo puro e simples da efetividade jurídica, mas utiliza-se dela como instrumento para melhor observar o sistema processual.

Surge, então, a indagação sobre o modo como as práticas procedimentais e os desdobramentos da ciência processual interferem na efetividade da tutela judicial, ou seja, na sua concretude. Nisso consiste a importância em explanar sobre alguns dos principais componentes da processualística civil, de modo que sejam esclarecidos esses aspectos na busca da efetividade.

Toda delimitação exige pontos de concentração e disto se infere a impossibilidade de esgotar todo o tema da Efetividade, mas sim seus aspectos cruciais. Por isso foram escolhidas três questões para o desdobramento do assunto: as formas e o formalismo dentro do processo, a consciência jurídica e a renovação processual.

Contudo, uma advertência deve ser feita: este estudo é programático. Não são definidos aqui institutos jurídico-procedimentais específicos ou indicadas novas estruturas para os procedimentos. A preocupação é diagnosticar como o panorama que envolve o atual Processo Civilinterfere nas modificações almejadas pelos jurisdicionados, a fim de efetivar as tutelas.

Diante dessa forma de abordagem e tendo em vista que a preocupação central é alcançar a efetividade do exercício da Jurisdição, mais especificamente da tutela processual, deve-se ter como norte as normas programáticas, baseadas nos princípios e diretrizes constitucionais.

Corroborando com este entendimento, Toffanello (2008):

As normas constitucionais programáticas não regulam diretamente a matéria que se referem, mas regulam propriamente a atividade estatal concernente a ditas matérias. Tem por objeto imediato os comportamentos estatais e só mediatamente, ou em segundo grau, aquelas determinadas matérias. Em rigor, a norma programática vincula comportamentos públicos futuros, estabelecendo premissas destinadas a vincular o desdobramento da ação legislativa dos órgãos estatais, assim como, regulamentar certa ordem de relações. É sem dúvida a categoria de normas constitucionais onde paira maior dúvida quanto a sua eficácia.

\subsection{A ESTRUTURA PROCESSUAL E O FORMALISMO NA ATIVIDADE JURISDICIONAL}

O processo de um modo geral é o método de instrumentalizar a Jurisdição. Para isso ele se vale dos seus meios próprios, quais sejam, as formas processuais. Estes aparatos devem exteriorizar e levar até o objetivo fundamental da demanda judicial que é a atuação do Estado-Juiz compondo litígios pela via mais adequada. 
Segundo o professor Carlos Alberto Álvaro de Oliveira (2008, p.2):

O formalismo, ou forma em sentido amplo, não se confunde com a forma do ato processual individualmente considerado. Diz respeito à totalidade formal do processo, compreendendo não só a forma, ou as formalidades, mas especialmente a delimitação dos poderes, faculdades e deveres dos sujeitos processuais, coordenação de sua atividade, ordenação do procedimento e organização do processo, com vistas a que sejam atingidas suas finalidades primordiais.

A forma, tanto constitui a capacidade de ser instrumento da jurisdição, quanto também de assegurar a legalidade do procedimento. Portanto, elaprovém do princípio do Devido Processo Legal, figurando como garantia da justa aplicação do ordenamento jurídico ao caso concreto. No mesmo sentido o professor Álvaro de Oliveira (2008, p.4):

O fenômeno oferece duas facetas: no plano normativo, impõe uma equilibrada distribuição de poderes entre as partes, sob pena de tornar-se o contraditório uma sombra vã; no plano do fato, ou seja, do desenvolvimento concreto do procedimento, reclama o exercício de poderes pelo sujeito, de modo a que sempre fique garantido o exercício dos poderes do outro. $\mathrm{O}$ justo equilíbrio presta-se, portanto, para atribuir às partes, na mesma medida, poderes, faculdades e deveres, de modo a que não seja idealmente diversa sua possível influência no desenvolvimento do procedimento e na atividade cognitiva do juiz, faceta assaz importante da própria garantia fundamental do contraditório.

Portanto, desmistificando a visão que já se tem sobre o formalismo processual, este não possui o caráter somente negativo, como se percebe muitas vezes, mas constitui importante ferramenta de efetivação dos direitos e validação da Jurisdição. Esta espécie de formalismo o professor Oliveira (2008, p.7) identifica como formalismo valorativo. Nessa modalidade, em contraposição ao formalismo excessivo, não se enfatizam as formas em si mesmas, mas sim a substância que compõe as técnicas procedimentais.

Das considerações até agora realizadas, verifica-se que o formalismo, ao contrário do que geralmente se pensa, constitui o elemento fundador tanto da efetividade quanto da segurança do processo. A efetividade decorre, nesse contexto, do seu poder organizador e ordenador (a desordem, o caos, a confusão decididamente não colaboram para um processo ágil e eficaz), a segurança decorre do seu poder disciplinador. Sucede, apenas, que ao 
longo do tempo o termo sofreu desgaste e passou a simbolizar apenas o formalismo excessivo, de caráter essencialmente negativo (OLIVEIRA, 2008, p.5).

Com isso não se desprestigia a experiência jurídica das técnicas e práticas já se dimentadas,muito menos a segurança que delas se extrai. Esta metodologia de um formalismo que reverencie o substrato dos mecanismos, busca dar real sentido e aplicabilidade às próprias técnicaspara que elasnão se tornem um fim em si mesmas.

No que tange à segurança que as formas proporcionam, esta característica não pode descambar para o aspecto da imutabilidade, a fim de evitar que sejam imobilizados os direitos dos indivíduos (OLIVEIRA, 2008, pp.11-12). Do mesmo modo, não se pode pretender com as formas a uniformização do Direito. Neste ponto, a efetividade é que deve ser o norte.

Seria temerário considerar que em todo centro de Jurisdição neste país fosse possível se coordenar o método de aplicação jurídica, seja no que toca à procedimentalidade, seja no que atine à aplicação do Direito em concreto. Até mesmo as formas, enquanto meios de alcançar a composição da contenda, precisam ser interpretadas e não uniformizadas em seu entendimento, daí é que surge a dinamicidade do Direito. É para isto que também existe a forma: garantir que a liberdade interpretativa seja posta em prática.

Observe-se bem que tal liberdade não pode se converter em um ativismo, pois acabaria saindo do extremo do formalismo para o abuso da informalidade. É cediço que muitas nulidades procedimentais são consideradas filigranas jurídicas possíveis de ser superadas. Isto, entretanto não se dá de imediato. Deve ser feito, para isso, um esforço argumentativo no sentido de demonstrar que tal questão pode ser relativizada, a fim de evitar um entrave no processo. Sobre este prisma processual diz Luciano Santos (2012, p.3):

Assim como se fala em formalismo excessivo também é possível falar-se em substancialismo excessivo. Até porque o conteúdo substancial dos valores depende da visão subjetiva de cada indivíduo e uma abolição exacerbada da forma terminaria por privilegiar somente os mais fortes, capazes de impor sua visão aos demais indivíduos.A relativização ou afastamento da forma deverá sempre incorrer num ônus de argumentação pela parte que a pretende.[...] Enfim, deve-se buscar privilegiar a substância sobre a forma, mas mantendo-se o equilíbrio para não incorrer em arbitrariedades ou decisionismo. Mas para que tal objetivo venha a se concretizar faz-se necessário passar da teoria para a prática com a incorporação nas decisões judiciais das regras discutidas no debate teórico acerca da argumentação jurídica. 
O operador do Direito é o artesão jurídico e seu instrumento de trabalho é a argumentação. Este é o meio do qual ele deve se valer para que seja feita a ponderação da atividade jurisdicional. Desse modo, a efetividade que é pretendida dentro do processo pode ser alcançada, sendo a formalidade uma via adequada para isso, desde que sem rigorismos. Aquilo que não limita a regularidade do processo, e pode ser suprido, não deve se constituir como foco e ato central,sob o prejuízo de se estabelecer a forma pela forma e a inefetividade processual.

\subsection{A CONSCIÊNCIA JURídiCA Na APLICAÇão do Direito}

O estudo do Direito é eminentemente uma investigação do aspecto humano da sociedade. As normas criadas para regulamentar condutas tem como fator constitutivo o próprio indivíduo, destinatário delas. Por isso a importância de observar os sujeitosque constituem esse sistema. $\mathrm{O}$ ordenamento não é estruturado somente por formas e procedimentos, mas há algo mais subjetivo que faz parte de cada agente.

Nisto está presente um aspecto que sustenta fortemente e faz parte da sistemática jurídica atual que é a consciência jurídica daqueles que estão em contato com a Jurisdição. Mesmo diante de análise que privilegie uma observação especificamente jurídica, não se pode desconsiderar o aspecto que toca à individualidade e subjetividade envolvida na interpretação ou aplicação dos regramentos. Por conseguinte, a efetividade da jurisdição passa também por este aspecto, porque a interpretação do direito que se aplicaé fator crucial para a concretização das tutelas pretendidas.

É preciso implantar um novo 'método de pensamento', rompendo definitivamente com as velhas posturas introspectivas do sistema e abrindo os olhos para a realidade da vida que passa fora do processo. É indispensável colher do mundo político e do social a essência dos valores ali vigorantes, seja para a interpretação das leis que temos postas, seja para com suficiente sensibilidade e espírito crítico chegar a novas soluções a propor;[...] (DINAMARCO, 2002, pp. 331-332).

Consciência jurídica é o termo aqui usado para definir a cultura, as práticas, a filosofia procedimental, enfim o conjunto de situações que envolvem o indivíduo que tem contato com a Jurisdição. Não podemos perder de vista que as bases científicas que fundamentam o Direito, e mais especificamente o Direito Processual Civil, devem compor o pensamento contemporâneo dos intérpretes. Por meio delas, deve ser possível também se alcançar os objetivos gerais desta ciência, dentre eles a efetividade.

Importante perceber que as escolhas jurídicas que são tomadas, tanto pelos operadores do direito, quanto pelos que institucionalizam as normas, envolvem em algum momento um grau de decisão na posição a ser adotada. Esta opção jurídica, 
desde a mais simples - como a forma de interposição de um recurso - até o ato complexo de opção política do legislador, interfere diretamente na pretensão levada pelo cidadão ao Judiciário. Percebe-se então que a renovação jurídica não passa somente pela mudança de postura dos agentes da Jurisdição, mas da sociedade como um todo.

A renovação faz parte de um trabalho do indivíduo, pois à medida que ele compreende o sistema no qual está inserido aplica um esforço no sentido de buscar colaborar com a efetivação das tutelas pretendidas. De igual modo, o incentivo a esta atitude do sujeito diante da jurisdição deve vir do Estado (juiz, executor e normatizador), para que a sociedade possa assimilar, através da implementação de uma cultura jurídica renovada, o que pretende e qual o verdadeiro papel da Jurisdição.

Ir ao Judiciário com a visão voltada para a Efetividade aclara tanto a visão das partes do litígio, quanto dos aplicadores do Direito, pois ambos fiscalizam-se mutuamente nos papéis que exercem. Consequência disto é uma conscientização dos jurisdicionados e dos aplicadores do Direito. Os primeiros não devem atravancar o processo com pretensões inócuas e estes últimos devem ter, no momento de sua atuação, uma visão ampla voltada para os objetivos gerais e não apenas para técnicas ou práticas despiciendas.

Velhos formalismos e hábitos comodistas minam o sistema e de um momento para o outro ele não se alterará. Além disso, a própria lei reflete atitudes privatistas e individualistas perante o processo, incluindo-se nisso o conformismo com algumas de suas supostas fraquezas e pouca disposição a superá-las. Para o exame crítico do sistema existente, é indispensável identificar os pontos vitais em que tomadas de posição se mostram particularmente importantes, considerando o tempo presente e o que hoje é lícito esperar do processo (DINAMARCO, 2002, p.333).

Neste panorama, relembrando as premissas já expostas por Barbosa Moreira no que toca a efetividade, é possível complementá-las com aquelas apontadas Luciana Drimel Dias (2009, pp.692-693) na sua investigação sobre o poder-dever jurisdicional:

São importantes alguns pontos para a reflexão: a) A reeducação quanto ao papel do judiciário perante os jurisdicionados com a consequente reestruturação de sua função que deve passar de precipuamente decisória, a uma função mais apaziguadora ("curativa") e, portanto, mediadora [...] b) O acompanhamento da função decisória; deve-se pois identificar o processo de transformação desse conflito no âmbito judiciário, desde a sua recepção nos limites processuais até a decisão final do magistrado, porem de forma mais lúcida, desvestindo-se de dogmas seculares que ofuscam a visão real do fenômeno. [...] Em outras palavras significa analisar o pro- 
cesso judicial sob bases não apenas dogmáticas mas sim críticas do ponto de vista da sociologia, economia, política a fim de perceber de onde vem o conflito e como ele se transforma[...] Ou seja para desempenhar este papel, deve este magistrado ser um juiz sensível a sua condição humana e consequentemente dos demais e ativista ao ponto de ir para além do seu papel iluminista de boca da lei.[...] c) A responsabilidade do magistrado, do criador da decisão judicial - há que se conscientizar que o judiciário não pode estar isento do crivo social, político e jurídico na medida do incremento do se poder (checksand balances).

Assim como a definição acima enfoca de forma marcante a importância do magistrado nesse papel de conscientização, os demais operadores do direito possuem relevância similar. Desde o Procurador da República, passando pelo Advogado do Estado, o Defensor Público e o Advogado particular. Todos esses envolvidos no litígio devem, como partícipes do Judiciário, desenvolver também, cada um ao seu momento, uma função educativa e formadora desta consciência. Tal atividade plenifica cada vez mais o sistema jurídico, do qual se busca maior a efetividade.

A educação através do adequado exercício da jurisdição é assim, portanto, um escopo instrumental do processo, ou seja, um objetivo a ser conseguido com a finalidade de chamar a própria população a trazer as suas insatisfações a serem remediadas em juízo. O escopo último continua sendo a pacificação social, que, na medida em eu obtidos bons níveis de confiança no seio da população, torna-se também mais fácil de ser levada a níveis satisfatórios (DINAMARCO, 2002, p.198).

Para que isso se concretize, portanto, é preciso um trabalho intensivo. Aí se inserem, além dos operadores do direito, os agentes públicos de um modo geral. O Estado tem o dever de fazer um trabalho de base iniciando-o pelo seu corpo de funcionários, porque estes também se envolvem na demanda. Esta é uma tarefa fundamental a ser desenvolvida justamente por ser ele o detentor da Jurisdição, devendo, deste modo, zelar pelo aperfeiçoamento de todos os elementos que a constituem, inclusive dos seus membros.

Nota-se a importância de uma renovação da consciência e a necessidade de pô-la em prática. Um programa de medidas neste sentido seria a abertura para chegar à gestão mais adequada da jurisdição e das atividades estatais como meio de fomentar nova mentalidade social. É possível trazer as tutelas pretendidas para uma ordem mais efetiva quando estão associados o aspecto teleológico da consciência jurídica e o trabalho prático de acentuar as bases que sustentam a Jurisdição. Isso serve como exemplo para indicar aos cidadãos a qualidade dos serviços jurisdicionais que eles devem buscar e, oferecendo-lhes tais atividades, apontar o modo mais efetivo 
possível de executá-las.

A consciência jurídica, então, faz parte de uma cadeia de fatores que se entrelaçam a fim de que sejam concretizadas, em primeiro lugar, as garantias constitucionais que as tutelas asseguram aos jurisdicionados.

\subsection{INOVAÇÃO PROCESSUAL: MOTIVOS E REPERCUSSÃO NA JURISDIÇÃO}

Inovar uma legislação significa mudar não somente a procedimentalidade das normas, mas também o sistema jurídico que existe em torno delas. Por isso a importância de visualizar o que seria o Princípio da Efetividade. Entende-se que a efetividade é regra referencial para que os objetivos da processualística sejam atingidos, portanto é necessário que a modificação legislativa esteja inserida nesse contexto.

Renovar a técnica processual é discussão de grande importância na atual conjuntura, mas se não for observado o paradigma da Efetividade, esta inovação não possuirá qualquer efeito prático. Os legisladores continuarão discutindo nomenclaturas, enquanto os jurisdicionados estarão ávidos por práticas mais efetivas.

As normas operam sobre a realidade conforme o valor que lhes é atribuído pelos princípios. As normas processuais relacionadas ao direito de ação, especialmente em razão da sua natureza instrumental, não podem se desligar dos vários casos concretos e assim devem ser lidas á luz do direito fundamental à tutela jurisdicional efetiva. [...] O ordenamento jurídico ao dispor de normas, exatamente porque sabe que não pode atender à todas as situações, diante da riqueza e multiplicidade das particularidades do caso concreto e, assim, respondem a um direito voltado à realidade, expressando um ordenamento jurídico marcado pelos princípios e pelos direitos fundamentais (MARINONI, 2009, p.143).

Quando se fala em mudança processual na sociedade atual, há uma série de fatores que interferem nesta realidade. Os fatores políticos, como já citados anteriormente, são os que determinam em grande parte as escolhas legislativas que hão de ser feitas. Portanto, as leis processuais também são o reflexo do momento legislativo que vive o país. Neste contexto, verifica-se que grande é o desejo da nação e de cada cidadão de ver a jurisdição e os seus direitos cada vez mais efetivos.

Os manifestos que têm levado os cidadãos às ruas do país é um exemplo prático de que a efetividade dos direitos é um anseio presente em muitos campos da sociedade. Entretanto, assim como não se pode considerar o processo como fim em si mesmo, isto não deve acontecer também em relação à mudança jurídica.

Nisto se percebe que deve ser observado um aspecto finalístico diante de qualquer mudança e como já indicava Capelletti (2002, p.161): "É preciso que reconheça que as reformas judiciais e processuais não são substitutos suficientes para as 
reformas políticas e sociais.”.

Há que se tratar então de dois aspectos desta renovação: o aspecto prático, aquele almejado por toda a sociedade nas tutelasconcedidas e o aspecto teleológico, relacionado com o sentido das normas e os princípios da Jurisdição. Um não se sustenta sem o outro, e diante deles percebe-se que, no fundo, trata-se de uma questão principiológica. As normas programáticas servirão de indicadores para os reformistas pautarem sua atuação, e aqui indica-se de forma primordial o princípio da Efetividade na processualística civil.

É temerário que as atuais mudanças, que há muito já vêm sendo lapidadas, ganhem um impulso fugaz objetivando dar uma resposta imediata à sociedade ou tentando suprir lacunas com soluções paliativas. O processo civil precisa de uma renovação de sentido, devendo ser repensada, primordialmente, a Jurisdição e o desenvolvimento do seu papel no contexto atual.

Não basta, portanto, renovar institutos para atingir objetivos específicos. Uma demonstração disto é a inserção da Emenda Constitucional 45 de 2004. Embora ela tenha trazido inovações positivas na sistemática jurídica, institucionalizou a definição de metas numerárias para os processos, o que não representa o seu objetivo final, que muito antes de tratar de estatísticas envolve seres humanos e situações peculiares.

Não é que com isso se desconsidere a importância da análise empírica, mas só ela não basta para chegar às conclusões corretas a respeito dos fatos. Uma junção de informações não tem o condão de ampliar a visão, senão quando tal estudo está atrelado ao que dá origem à técnica observada. Sem analisar o fundamento daquilo que constitui a prática, a investigação se perde no emaranhado de dados que se possa obter. É necessário entender o porquê de determinado funcionamento e a partir daí suas conclusões estatísticaspoderão levar a resultados mais exatos e realistas. Isso depende também de um trabalho interno.

É nesta espécie de reforma que se concentra a atenção. O aperfeiçoamento de paradigmas a fim de que as velhas estruturas não deixem o processo corroer à pura e simples procedimentalidade e operacionalidade. A reforma que se espera é esta. Mas não cabe somente pensar que ela virá de uma mudança na legislação. Os fatores já explanados anteriormente demonstram que as três estruturasde poder tem influência direta numa verdadeira efetividade processual. Elas interferem também na mudança de conceitos e na tomada de novas posturas, surgindo com a aplicação do direito pelo judiciário, passando pela atividade mais adequada e menos mecanicista da administração pública até que tais mudanças sejam o alvo para uma dogmática legislativa inspirada em tais contextos.

$\mathrm{O}$ instrumento processual, com efeito, não depende unicamente do que está legalmente estabelecido, mas de como é "manuseado" na prática aquilo que está no direito posto. Daí porque a legislação não deve ser execrada em uma esfera particular. As mudanças que se almejam não dependemunicamente dela, mas são 
construções que vem sendo feitas ao longo do tempo e com a colaboração de todos aqueles que são partícipes da Justiça.

Um poder do Estado sozinho não tem a capacidade de criar, operacionalizar e instituiras mudanças pretendidas em um único ato. É necessária a colaboração e participação das demais esferas estatais para que o problema global da efetividade, reduzida aos procedimentos e ao direito em concreto, seja debelada de forma coesa. Isto se dá por uma renovação na atuação dos membros do Executivo Estatal, dos que compõem a Jurisdição e também daqueles que elaboram as leis.

Portanto, esta união de fatores é que pode garantir que no momento em que a legislação chegue à sua propriamente dita inovação ela esteja munida de todos os subsídios citados. São eles que sustentam uma base sólida de aplicação do direito ao caso concreto.

\section{Conclusões}

O estudo do Princípio da Efetividade dentro da Jurisdição buscou aclarar a visão dos operadores do direito para a necessidade premente que se tem de concretizar as tutelas jurisdicionais.

O caminho para chegar à efetivação dos Direitos foi delineado. O primeiro passo para a maior aplicabilidade é que a Jurisdição tenha, na prática, como principal objetivo a efetividade processual. É através do Princípio da Efetividade que as tarefas assumidas pelo Estado-juiz podem ser respondidas verdadeiramente, levando as partes à condição mais adequada possível na demanda. Nesta toada, não basta uma porta de entrada para o Judiciário que seja efetiva, importa também que os direitos alcançados através da tutela estatal sejam igualmente efetivos.

Colocar a Efetividade no centro da Jurisdição é concretizar, também, a pacificação social, mote do processo civil. Pode-se chegar a isso com os próprios instrumentos processuais existentes, poisestes quando bem utilizados aperfeiçoam a tarefa do Judiciário. Exemplo disso são as formalidades processuais que são garantias asseguradas às partes, mas se consideradas como um fim em si mesmas podem caracterizar brechas que levam à morosidade e inefetividade das medidas tomadas.

Outro ponto a se destacar é afunção dos indivíduos que estão envolvidos na demanda. Os partícipes do processo, seja em que nível for, colaboram para a construção de uma consciência jurídica. Isso envolve desde o serventuário da Justiça até um terceiro interveniente num processo, desde o juiz até o legislador, enfim todos aqueles que de algum modo ajudam a construir a máquina jurisdicional. Portanto, o trabalho envolve um empenho social em desfazer velhas práticas que não contribuem para uma processualística fluida e reavivar os objetivos primeiros da Jurisdição. É por isso que os princípios possuem extrema importância numa análise como esta, pois eles são fomentadores e propulsores de uma renovada interpretação do que já está solidificado. Essa ênfase numa mentalidade nova assegura maior legitimidade para 
o Judiciário devido a uma melhor compreensão e contribuição dos jurisdicionados e dos membros da Justiça na tarefa jurisdicional.

Vislumbrara Jurisdição mais efetiva é não perder de vista o movimento de renovação processual, que influi diretamente na regulamentação das tutelas. Este anseio por uma maior concretude judicial se traduz nas propostas de inovações legislativas, contudo é temerário pensar em mudanças sem que existam fundamentos teóricos para tal. É necessário que num programa de mudanças esteja sedimentado que a estrutura legislativa precisa de uma renovação de sentido e aplicabilidade, pois a mudança da técnica por si mesma não assegura a concretude das tutelas pretendidas.

Com efeito, visualizar a Jurisdição pelo padrão da efetividade significa associar uma série de fatores para tornar o papel do Judiciário o mais humanizado possível. Necessário se faz o empenho de todos os agentes sociais para que essa possa ser uma realidade concreta nas tutelas almejadas na Processualística civil atual.

\section{REFERÊNCIAS}

CÂMARA, Alexandre Freitas. Bases Teóricas Para Um Novo Código de Processo Civil. In: CALMON, Petrônio; CARNEIRO, Athos Gusmão (Org.). Bases Cientificas Para Um Renovado Direito Processual. Salvador: JusPODIVM, 2009. DIDIER JUNIOR, Fredie. Curso de direito processual civil: teoria geral do processo e processo de conhecimento. 11. ed. Salvador, BA: Edições JusPODIVM, 2009. v. 1

DIAS, Luciana Drimel. Considerações sobre uma possível equalização do binômio poder-dever jurisdicional. In: CALMON, Petrônio; CARNEIRO, Athos Gusmão (Org.). Bases Cientificas Para Um Renovado Direito Processual. Salvador: JusPODIVM, 2009.

DINAMARCO, Cândido Rangel. A instrumentalidade do processo. 10. ed., rev. e atual. São Paulo: Malheiros, 2002.

FERREIRA, Aurélio Buarque de Holanda. Novo Dicionário Eletrônico Aurélio Versão 5.0. 3. ed. S.L: Editora Positivo, 2004.

KELSEN, Hans. Teoria pura do direito. 5. ed. São Paulo: Livraria Martins Fontes, 1997.

MARINONI, Luiz Guilherme. Ideias para um "renovado direito processual". In: CALMON, Petrônio; CARNEIRO, Athos Gusmão (Org.). Bases Científicas Para Um Renovado Direito Processual. Salvador: JusPODIVM, 2009.

NADER, Paulo. Introdução ao estudo do direito. 32. ed. Rio de Janeiro: Forense, 2009.

OLIVEIRA, Carlos Alberto Álvaro de. O formalismo-valorativo no confronto com o formalismo excessivo, s.n, [2008]. Disponível em: http://alvarodeoliveira.com.br/ 
site/?p=192. Acessado em: 05.09.2013

SANTOS, Luciano Roberto Bandeira. Substancialismo, formalismo e argumentação jurídica. Jus Navigandi, Teresina, ano 17, n. 3311, 25 jul. 2012. Disponível em: http://jus.com.br/artigos/22259. Acessado em: 04.09.2013.

TOFFANELLO, Rafael Dias. Eficácia jurídica das normas constitucionais programáticas. Teixeira Ribeiro Advogados, s.no , [2005]. Disponível em: http://www.teixeiraribeiro.com/arquivos/rdt_art_eficacia_juridica_das_normas_constitucionais_ programaticas.pdf. Acessado em: 03.09 .2013 . 